\title{
Study of depot medroxyprogesterone acetate as an extended postpartum contraceptive at SCB medical college and hospital, Cuttack
}

\author{
Sagarika Samal*, Lucy Das
}

Department of Obstetrics and Gynecology, SCB Medical College and Hospital, Cuttack, Odisha, India

Received: 14 January 2021

Revised: 16 February 2021

Accepted: 26 February 2021

\author{
*Correspondence: \\ Dr. Sagarika Samal, \\ E-mail: sagarikaeeba@gmail.com
}

Copyright: (c) the author(s), publisher and licensee Medip Academy. This is an open-access article distributed under the terms of the Creative Commons Attribution Non-Commercial License, which permits unrestricted non-commercial use, distribution, and reproduction in any medium, provided the original work is properly cited.

\begin{abstract}
Background: Increase in contraceptive use during the postpartum period substantially reduces the rate of maternal and infant mortality by preventing unplanned and unwanted pregnancies. Injectable Medroxy Progesterone acetate (DMPA) is one long acting reversible safe and effective method for postpartm contraception. Aims and Objectives to study the acceptance, efficacy, side effects and compliance of DMPA as an extended postpartum contraceptive at SCB Medical College, Cuttack.

Methods: The study includes 76 women between 6weeks to 1year postpartum who had chosen DMPA as contraceptive after counseling regarding the basket of choices. DMPA injection was given within 7 days of menstruation if it has returned or at any time after being confirmed that woman is not pregnant with a back up for first 7days. Subsequent injections were given at three monthly intervals and followed up for one year after the first injection for pregnancy rate, side-effects, discontinuation and patient satisfaction.

Results: Maximum females were from the combined age groups 25-29 (39.47\%) and 20-24 years (35.52\%). 46.1\% women belong to lower middle socioeconomic group. The most common menstrual problem was amenorrhea in $47.36 \%$ followed by scanty bleeding in $22.36 \% .25 \%$ discontinued after 1 st dose of injection, which is the maximum. The commonest reason for discontinuation observed was menstrual problems $(37.93 \%)$ followed by use of other methods of contraception (17.24\%). Out of 76, 23 women were not satisfied (30.26\%), main reason of dissatisfaction being menstrual problems. Failure rate was nil.

Conclusions: The study concludes that DMPA is a very effective, safe, and long acting contraceptive with no effect on lactation. Proper counseling can improve the acceptance and compliance.
\end{abstract}

Keywords: Acceptability, Compliance, Contraception, DMPA, Side effects

\section{INTRODUCTION}

Population explosion today is a major concern and an impending disaster. India is the second most populated country in the world with nearly a fifth of the world's population of around 138 crores. The major cause of population growth is high birth rate due to poverty, illiteracy, cultural norms, early marriage, sexual activity and behavior. The important determinants being higher proportion of women in reproductive age group (50\%) and higher fertility due to unmet need for contraception.
According to the WHO, approximately 830 women die every day from preventable causes related to pregnancy and childbirth. The SDG target 3.1 is to reduce global maternal mortality ratio to less than 70 per 100,000 live births by $2030 .{ }^{1}$ UNFPA study has estimated that if current unmet need for contraception could be fulfilled within next 5years, country can avert 35000 maternal deaths and 12lakh infant deaths. ${ }^{2}$ More than $30 \%$ of maternal deaths and $10 \%$ of child mortality can be staved off if couples space their pregnancies more than 2 years apart by Cleland et al. ${ }^{3}$ The contraceptive prevalence rate 
(CPR) is 54 percent of currently married women age 15$49 .{ }^{4}$ NFHS-4 states that almost $13 \%$ of women have an unmet need for family planning including a $6 \%$ unmet need for spacing and $7 \%$ for limiting in India.

Postpartum family planning (PPFP) is defined as the prevention of unintended pregnancy and closely spaced pregnancies through the first 12 months following childbirth. It can be post placental (with in 10min after placental delivery), immediate postpartum (with in 48hours), early postpartum (48hours-6weeks), extended postpartum (6weeks-1year).

MPA (Medroxy Progesterone Acetate) is a synthetic progesterone, an injectable contraceptive method. ${ }^{5}$ Under the National family planning programme it has been added to the basket of choice (Antara Program). It inhibits secretion of pituitary gonadotropins, preventing follicular maturation and ovulation by suppressing the mid cycle LH peak. ${ }^{6,7}$ Single dose of $150 \mathrm{mg}$ IM will suppress ovulation in most women for more than 14 weeks. It also causes cervical mucus thick and viscid preventing sperm penetration ${ }^{8}$ and endometrium atrophic making it unfavorable for blastocyst implantation.

\section{Dose}

$150 \mathrm{mg}$ intramuscular every 3 months or $300 \mathrm{mg}$ every 6 months.

It is a highly effective contraceptive with perfect use failure rate $0.3 \%$ with good safety profile. Long acting acts for 3 months with a grace period of 4 weeks, completely reversible within 7-10 months from the date of last injection. ${ }^{9,10}$

It doesn't interfere with lactation and is suitable as a postpartum contraceptive. Doesn't require daily routine or additional supplements. Doesn't interfere with sexual intercourse and pleasure. No Estrogen related side effects. No increased risk of deep vein thrombosis, pulmonary embolism, stroke, or myocardial infarction. Long-term DMPA use decreases the incidence of pelvic inflammatory disease, and lowers the risk of endometrial cancer.

The administration of Depo-Provera usually causes disruption of the normal menstrual cycle. ${ }^{11}$ Bleeding patterns include amenorrhea (present in up to $30 \%$ of women during the first 3 months and increasing to $55 \%$ by month 12 and $68 \%$ by month $24 \& 80 \%$ by 3years) ,irregular bleeding and spotting, prolonged (>10 days) episodes of bleeding, rarely heavy prolonged bleeding may occur. Other adverse effects include loss of bone mineral density with long term use. ${ }^{12}$ It is reversible and most bone lost is restored within 5years of stoppage, weight gain, headache, women with insulin resistance may develop diabetes.
Aim of study was to the acceptance, efficacy, side effects and compliance of DMPA as an extended postpartum contraceptive.

Objectives of the study was to know the contraceptive method used by the women of urban and rural population. To determine the factors associated with their acceptability according to their socio-demographic and obstetric characteristics. To determine the failure rate. To evaluate the maternal complications during postpartum period after use of this method. Rate of continuation and causes of discontinuation. To assess the degree of client satisfaction with this method.

\section{METHODS}

\section{Inclusion criteria}

Women of any age and parity seeking contraception between 6 weeks to 1year post delivery.

\section{Exclusion criteria}

Those who didn't give consent for enrollment and regular follow up. Multiple risk factors for cardiovascular diseases (diabetes, hypertension, dyslipidemia). Severe hypertension $(\mathrm{BP}>=160 / 100 \mathrm{mmHg}$ ). Current or history of ischemic heart disease and stroke. Acute deep vein thrombosis or pulmonary embolism. Diabetes mellitus with nephropathy/ neuropathy/ retinopathy or diabetes $>20$ years. Unexplained vaginal bleeding. Severe decompensated cirrhosis and hepatic tumors. Migraine with aura. Current or past breast cancer.

\section{Method of data collection}

The study was conducted at Dept of O \& G, SCB Medical College and Hospital, Cuttack from 01.06.2018 to 30.11.2019. Eligible women were counseled and were given choices explaining well about the benefits and side effects of each contraceptive. Those who opted for DMPA were included in the study. Their socio demographic data, detailed history and physical examination were recorded in the predesigned questionnaire or performa. Inj DMPA 150mg deep IM was given and next doses subsequently at 3 monthly intervals. The first dose is given after 6weeks postpartum.

If she is fully or nearly fully breastfeeding and her monthly bleeding has not returned; can be started any time between 6 weeks and 6 months no need for a backup method. If she is partially breastfeeding or not breast feeding and her monthly bleeding has not returned after being certain that the woman is not pregnant and she will need a backup method (e.g. Condom) for the first 7 days after DMPA injection. If her monthly bleeding has returned, can be started any day within 7 days of menstrual cycle with no need for a backup method. It can also be started any time later in the menstrual cycle (after 7 days) after being certain that the woman is not pregnant 
with a backup method for the first 7 days after the injection.

For more than 6months postpartum, can be started at any time, if her monthly bleeding has not returned after being certain that the woman is not pregnant with a backup method (e.g. Condom) for the first 7 days. If her monthly bleeding has returned, she can start injectable as advised above.

They were followed at 3monthly intervals from the date of first injection for pregnancy, alteration in menstrual pattern, other side effects, patient satisfaction and reason if patient wants discontinuation.

\section{Type of study}

Observational Analytical Retrospective study.

Statistical tool used to analyse data: MS Excel (Office $365)$.

\section{RESULTS}

Table 1: Profile of study participants $(n=76)$.

\begin{tabular}{|c|c|c|}
\hline \multicolumn{2}{|l|}{ Characteristic } & $\begin{array}{l}\text { Mean } \pm \text { Std.Dev.* } \\
(\min -\max ) / \\
\text { Number }(\%)\end{array}$ \\
\hline \multicolumn{2}{|l|}{ Age (in years) } & $26.1 \pm 4.5(19-40)$ \\
\hline Religion & Non-Hindu & $19(25.0)$ \\
\hline $\begin{array}{l}\text { Employment } \\
\text { status }\end{array}$ & Employed & $13(17.1)$ \\
\hline $\begin{array}{l}\text { Place of } \\
\text { residence }\end{array}$ & Rural & $14(18.4)$ \\
\hline \multirow{3}{*}{$\begin{array}{l}\text { Socio- } \\
\text { economic } \\
\text { status }\end{array}$} & $\begin{array}{l}\text { Upper Lower } \\
\text { class }\end{array}$ & $30(39.5)$ \\
\hline & $\begin{array}{l}\text { Lower } \\
\text { Middle class }\end{array}$ & $35(46.1)$ \\
\hline & $\begin{array}{l}\text { Upper } \\
\text { Middle class }\end{array}$ & $11(14.5)$ \\
\hline \multirow{3}{*}{ Parity } & One & $36(47.36)$ \\
\hline & Two & $35(46.05)$ \\
\hline & Three & $5(6.57)$ \\
\hline $\begin{array}{l}\text { Mode of last } \\
\text { delivery }\end{array}$ & $\begin{array}{l}\text { Cesarean } \\
\text { section } \\
\text { VD }\end{array}$ & $\begin{array}{l}35(46.1) \\
41(53.94)\end{array}$ \\
\hline Breastfeeding & $\begin{array}{l}\text { Currently } \\
\text { feeding }\end{array}$ & $71(93.4)$ \\
\hline \multirow{5}{*}{$\begin{array}{l}\text { Contraceptives } \\
\text { last used }\end{array}$} & $\begin{array}{l}\text { Barrier } \\
\text { method }\end{array}$ & $12(15.8)$ \\
\hline & Copper T & $08(10.5)$ \\
\hline & $\begin{array}{l}\text { Oral } \\
\text { contraceptive } \\
\text { pills }\end{array}$ & 05 (06.6) \\
\hline & $\begin{array}{l}\text { Natural } \\
\text { method }\end{array}$ & $04(05.3)$ \\
\hline & None & $47(61.8)$ \\
\hline
\end{tabular}

Std. Dev.: standard deviation; min: minimum; max: maximum
Age is an important determinant for the use of contraception. Maximum females were from the combined age groups 25-29 (39.47\%) and 20-24 years $(35.52 \%)$. Mean age was found to be $26.1 \pm 4.5$. 57 were Hindu (75\%) and 19 were Muslims (25\%). $81.57 \%$ users dwelled in urban areas and $18.42 \%$ in rural areas. 63 women were housewives $(82.89 \%)$ and 13 were employed (17.10\%). 46.1\% women belong to lower middle socioeconomic group and $39.5 \%$ women belong to upper lower group. $63.15 \%$ of users were educated from primary up to matriculation. Only 2 users were illiterate. 36 women opted for DMPA after 1st child (47.36\%). 35 women opted after second child (46.05\%). 41 women took DMPA after vaginal delivery and 35 women after LSCS. $61.84 \%$ women have not used any kind of contraception. Barrier method was used by 12 couples, IUCD by 8 women, OCPs by 5 women and 4 couples were practicing natural method of contraception.

Table 2: Comparison of complications in all follow up.

\begin{tabular}{|llll|}
\hline Complication & $\begin{array}{l}1^{\text {st }} \text { follow } \\
\text { up } \%\end{array}$ & $\begin{array}{l}2^{\text {nd }} \text { follow } \\
\text { up }\end{array}$ & $\begin{array}{l}3^{\text {rd }} \text { follow } \\
\text { up } \%\end{array}$ \\
\hline $\begin{array}{l}\text { Irregular } \\
\text { bleeding }\end{array}$ & 13.15 & 6.66 & 3.33 \\
\hline $\begin{array}{l}\text { Delayed } \\
\text { periods }\end{array}$ & 9.21 & 13.33 & 16.66 \\
\hline $\begin{array}{l}\text { Heavy/ } \\
\text { prolonged } \\
\text { bleeding }\end{array}$ & 3.94 & 8.88 & 10 \\
\hline $\begin{array}{l}\text { Scanty } \\
\text { bleeding }\end{array}$ & 22.36 & 26.66 & 26.66 \\
\hline Amenorrhea & 47.36 & 66.66 & 83.33 \\
\hline Weight gain & 00 & 6.66 & 10 \\
\hline
\end{tabular}

$1^{\text {st }}$ follow up was done 3 months after the date of first injection. Out of 76, menstrual problems were seen in 64 women. 10 reported irregular bleeding, 7 delayed periods, 3 heavy/prolonged bleeding, 17 scanty bleeding and 36 reported amenorrhea 1-3 months following the first injection. So the most common menstrual problem was amenorrhea in $47.36 \%$ followed by scanty bleeding in $22.36 \%$. 12 women reported no complications (15.78\%). Headache was complained by a single woman, none complained of weight gain. Reduced milk secretion was seen in one woman.

$2^{\text {nd }}$ follow up was done 6 months after the date of first injection. 45 women were enrolled. $66.66 \%$ reported amenorrhea, $26.66 \%$ scanty bleeding and $13.33 \%$ delayed periods. Heavy bleeding was seen in $8.88 \%$ and irregular bleeding in $6.66 \%$. No side effects seen in only one woman. (2.22\%) Headache and reduced milk secretion was complained by the same one woman. Weight gain was reported by 3 females (6.66\%). 18\% discontinued after $2^{\text {nd }}$ dose injection.

$3^{\text {rd }}$ follow up was done 9months after the date of first injection. 30 women were enrolled. Percentage of women 
having amenorrhea was $83.33 \%$. Scanty bleeding was seen in $26.66 \%$, delayed periods in $16.66 \%$, heavy bleeding in $10 \%$, irregular bleeding in $3.33 \%$. Headache and reduced milk secretion was seen in the same one woman. 3 women complained of weight gain. $7 \%$ discontinued after 3 rd dose injection.

Affandi B et al in a study concluded that the main problem of long-acting progestogens is the disruption of the menstrual cycle. ${ }^{13}$
Chance of reporting a complication increased with each follow up visit. Women were also more likely to report an increasing number of co-existing complications as the number of follow up visits increased. Of the 30 participants in the 3rd follow up, all reported at least one complication.

The commonest reason for discontinuation observed was menstrual problems (37.93\%) followed by use of other methods of contraception (17.24\%).

Table 3: Correlation of no of complications with duration of follow up.

\begin{tabular}{|lllllll|}
\hline $\begin{array}{l}\text { Number of complications } \\
\text { reported }\end{array}$ & 1st follow up visit & \multicolumn{2}{c|}{ 2nd follow up visit } & \multicolumn{2}{c|}{ 3rd follow up visit } \\
\hline $\mathbf{0}$ & $\mathbf{N}$ & $\mathbf{\%}$ & $\mathbf{N}$ & $\mathbf{\%}$ & $\mathbf{N}$ & $\mathbf{\%}$ \\
\hline $\mathbf{1}$ & 12 & 15.8 & 2 & 4.4 & 0 & 0.0 \\
\hline $\mathbf{2}$ & 55 & 72.4 & 30 & 66.7 & 19 & 63.3 \\
\hline $\mathbf{3}$ & 7 & 9.2 & 10 & 22.2 & 7 & 23.3 \\
\hline $\mathbf{4}$ & 2 & 2.6 & 2 & 4.4 & 3 & 10.0 \\
\hline $\mathbf{5}$ & 0 & 0.0 & 1 & 2.2 & 0 & 0.0 \\
\hline Total & 0 & 0.0 & 0 & 0.0 & 1 & 3.3 \\
\hline
\end{tabular}

Table 4: Reasons for discontinuation.

\begin{tabular}{|lll|}
\hline Reason & Number & Percentage \\
\hline Menstrual problems & 11 & 37.93 \\
\hline Fear of amenorrhea & 3 & 10.34 \\
\hline Switched to other methods & 5 & 17.24 \\
\hline Household problems & 3 & 10.34 \\
\hline Transport problem & 1 & 3.44 \\
\hline Religion issues & 2 & 6.89 \\
\hline Not staying with husband & 1 & 3.44 \\
\hline Not specified & 1 & 3.44 \\
\hline Total & 27 & \\
\hline
\end{tabular}

Table 5: Discontinuation at each follow up.

\begin{tabular}{|llll|}
\hline $\begin{array}{l}\text { Follow } \\
\text { up }\end{array}$ & $\begin{array}{l}\text { Total no. } \\
\text { of female }\end{array}$ & Discontinued & Percentage \\
\hline $\mathbf{1}^{\text {st }}$ & 76 & 17 & 22.36 \\
\hline $\mathbf{2}^{\text {nd }}$ & 45 & 08 & 17.78 \\
\hline $\mathbf{3}^{\text {rd }}$ & 30 & 02 & 6.67 \\
\hline
\end{tabular}

5 females switched to other contraceptives, 2 opted for female sterilization, 2 for combined oral pills, one for Progestin only pills and one for IUCD.

Maximum discontinuation were after the 1st dose $(22.36 \%)$, which decreased to $17.78 \%$ after 2 nd dose and $6.67 \%$ after $3^{\text {rd }}$ dose.

Out of 76 DMPA users $30.26 \%$ were not satisfied, main reason of dissatisfaction being menstrual problems.
From the above table it was observed that demographic profile doesn't affect satisfaction significantly.

The trend of amenorrhea shows increase in the percentage of amenorrhea from 1st to 3rd follow up. Total amenorrhea obtained after 3 injections was $83.33 \%$. $\mathrm{p}$ value calculated for the trend was $<0.001$ suggesting chance of amenorrhea increases with no of months of exposure.

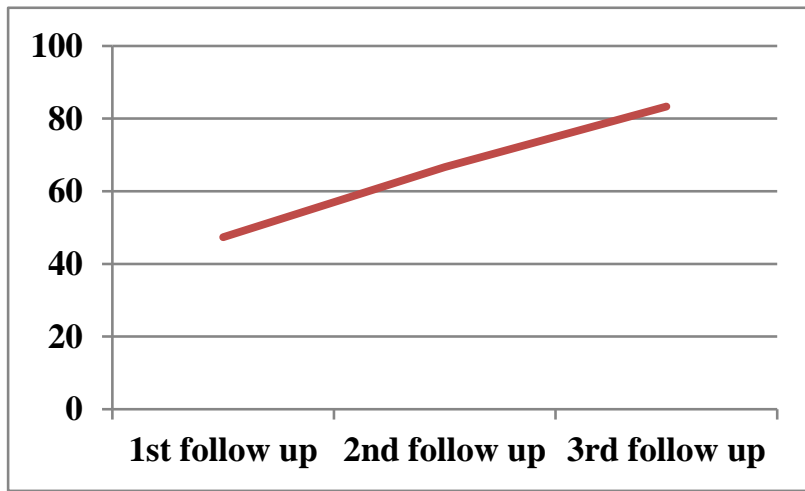

Figure 1: Graphical presentation of percentage of amenorhea in relation to no. of injections.

\section{Effectiveness}

Of all the women who were administered with inj DMPA, none of them got pregnant. Hence in our study failure rate was NIL. 
Table 6: Satisfaction.

\begin{tabular}{|lll|}
\hline Satisfaction & Number & Percentage \\
\hline Yes & 53 & 69.73 \\
\hline No & 23 & 30.26 \\
\hline Total & 76 & \\
\hline
\end{tabular}

Table 7: Correlation of satisfaction with patient profile.

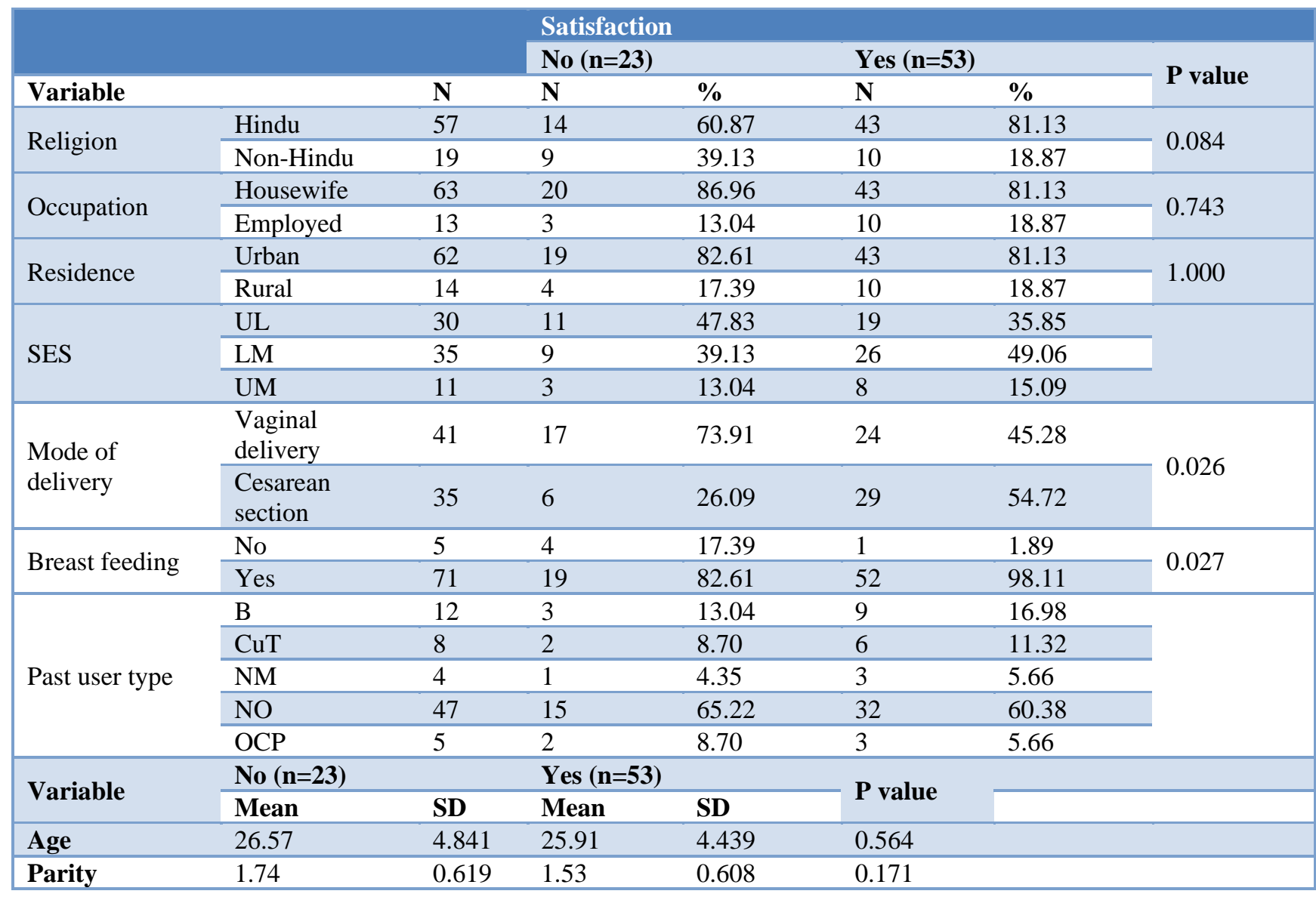

Table 8: Trend of amenorrhea (amenorrhea in relation to no of injections).

\begin{tabular}{|ll|}
\hline Amenorrhea & Percentage \\
\hline $\mathbf{1}^{\text {st }}$ follow up (after $\mathbf{1}^{\text {st }}$ inj) & 47.36 \\
\hline $\mathbf{2}^{\text {nd }}$ follow up (after $\mathbf{2}^{\text {nd }}$ inj) & 66.66 \\
\hline $\mathbf{3}^{\text {rd }}$ follow up (after $\mathbf{3}^{\text {rd }}$ inj) & 83.33 \\
\hline
\end{tabular}

Chi2 for trend $p$ value $<0.001$

\section{DISCUSSION}

In our study 30 women completed 9 month follow up which is higher than study of Sirisha P et al in which $36 \%$ women completed 12 month follow up. ${ }^{13}$

Affandi B. et al in a study concluded that the main problem of long-acting progestogens is the disruption of the menstrual cycle. ${ }^{14}$
In our study $38 \%$ women discontinued due to irregular bleeding which is lower than the study of Nair et al where irregular spotting occurred in $45 \%$ of women. Amenorrhea was seen in $65.3 \%$ of the women which was same as found by Nair et al where amenorrhea occurred in $65 \%$ of the women. In Nair et al discontinuation rate was $43 \%$. Similar drop out is seen in study of Fonsea et al and Aktun et al.

Aktun et al in a study found eight $(0.08 \%)$ pregnancies occurred, within 3 months of injection in 9262 women. Of 9262 cases, irregular bleeding occurred in $80 \%$ (7410) of the women. Discontinuation rate with this contraceptive method was recorded as $71 \%$ (6576) of the subjects. The rate of other predominant side effects were $8 \%$ for increase in weight, $8 \%$ for breast engorgement, $7 \%$ for mastalgia, $5 \%$ for headache. ${ }^{15}$ 
Lavanya et al, in their study concluded that, $70 \%$ of the women had irregular vaginal spotting and this was cited as the reason for discontinuation by almost $45 \%$ of these women. ${ }^{16}$ There were no reports of heavy bleeding. $65 \%$ developed amenorrhea which resulted in discontinuation in $11.7 \%$ of these women. Weight gain was only marginal and could not be attributed to DMPA alone. In postpartum women, lactation remained unaffected. The discontinuation rate was 42.5 per cent, all the discontinuations reported in the study was either after $1 \mathrm{st}$ or 2 nd injection when the menstrual irregularities were at their peak $16.65 \%$ of acceptors who completed the study said they would recommend this method to others because of convenience and privacy.

Ruminjo et al in a study of Comparative acceptability of combined and progestin-only injectable contraceptives in Kenya concluded that the 1-year continuation rate was $75.4 \%$ for Depo-Provera users. Main reasons for discontinuation included difficulty making clinic visits (40\%), menstrual changes $(12.5 \%)$ and non-menstrual problems (12.5\%). $70.6 \%$ of the Depo-Provera users were amenorrheic after 12 months. ${ }^{17}$

Wellings et al in a study showed half of respondents $(50.3 \%)$ thought that irregular bleeding deterred women from using LARC and $20.6 \%$ were concerned about high discontinuation rates. ${ }^{18}$

Aladag et al found satisfaction as one of the most important factors affecting contraceptive selection and its continuation. They also mentioned that satisfaction from a method is often influenced by frequency of side effects and the outcomes on individuals' health. ${ }^{19}$

Limitation: Sample size is small. Access to the clients was limited. Duration of study was brief. Cultural and social bias and other personal issues. Impact of the drug could not be assesed in the drop out population. Long term impact could not be assessed.

\section{Future scopes for DMPA}

DMPA can be promoted as a male contraceptive. Selfadministration of DMPA-SC is feasible, acceptable, effective and improves continuation only if it is made widely available and remains a true choice for women interested in this option. ${ }^{20}$

\section{CONCLUSION}

Complications associated with pregnancy and childbirth is the leading cause of morbidity and mortality among women of reproductive age, particularly in less developed countries and that is why maternal health is one of the most urgent global concerns. In this context, the postpartum period is particularly important for initiating contraception to space and limit births in a healthy manner. An increase in contraceptive use during the postpartum period substantially reduces the rates of maternal and infant mortality by preventing unplanned and unwanted pregnancies.

Contraception is always associated with apprehension and misinformation and it is more in rural women due to their illiteracy, but with proper selection of cases with good counseling and conscientious follow up compliance can be improved.

Promotion of family planning and ensuring access to preferred contraceptive methods for women and couples is essential to securing the well-being and autonomy of women, while supporting the health and development of communities.

\section{ACKNOWLEDGMENTS}

Authors would like to proud privilege to express author deep sense of gratitude to author esteemed teacher and guide, Prof. (Dr.) Lucy Das, Professor, Department of Obstetrics and Gynecology, S.C.B Medical college, Cuttack under whose personal supervision and constant guidance, this work has been accomplished. Author extremely obliged to my beloved Parents Mrs Geetanjali Samal and Mr. Shiva Prasad Samal for extending their unconditioned support, love, blessings and constant encouragement. Author extremely thankful to her beloved husband Dr. Deepak Padhi who has been a constant source of inspiration and perennial love. Author also thank all her friends and nears and dears for their kind words of encouragement.

Funding: No funding sources

Conflict of interest: None declared

Ethical approval: The study was approved by the Institutional Ethics Committee

\section{REFERENCES}

1. 2030 Agenda - Sustainable Development - the United Nations Available from https://sustainabledevelopment.un.org > post2015 > transformingourworld.

2. Family planning - MoHFW Available from https://mohfw.gov.in Chapter 915.

3. Family planning: the unfinished agenda*John Cleland, Stan Bernstein, Alex Ezeh, Anibal Faundes, Anna Glasier, Jolene Innis The Lancet 368(9549):1810-27 · December 2006 DOI: 10.1016/S0140-6736(06)69480-4 · Source: PubMed

4. National Family Health Survey (NFHS-4)rchiips.org $>$ nfhs > India

5. Injectable contraceptive (dmpa) - National Health Mission MP)https://www.nhmmp.gov.in , Guideline2017 > Injectable_Manual

6. Glasier A "Contraception". In DeGroot LJ, Jameson JL (eds.). Endocrinology (5 $5^{\text {th }}$ ed.). Philadelphia: Elsevier Saunders. 2006;2993.

7. Loose DS, Stancel GM "Estrogens and Progestins". In Brunton LL, Lazo JS, Parker KL (eds.). Goodman 
\& Gilman's The Pharmacological Basis of Therapeutics (11 ${ }^{\text {th }}$ ed.). New York: McGraw-Hill. 2006; 1541-71.

8. Rivera R, Yacobson I, Grimes D. The mechanism of action of hormonal contraceptives and intrauterine contraceptive devices". American J Obstetr Gynecol. 1999;181(5.1):1263-9.

9. Trussell J. Contraceptive efficacy. In Hatcher RA, Trussell J, Stewart FH, Nelson AL, Cates Jr W, Guest F, Kowal D. Contraceptive Technology, 17th ed (revised). New York, NY, Ardent Media, 2004: 773-845.

10. Westhoff C. Depot-medroxyprogesterone acetate injection (Depo-Provera): a highly effective contraceptive option with proven long-term safety". Contraception. 2003;68(2):75-87.

11. Machin D, Farley TM, Busca B, Campbell MJ, d'Arcangues C. Assessing changes in vaginal bleeding patterns in contracepting women. Contraception. 1988;38(2):165-79.

12. Kaunitz AM, Miller PD, Rice VM, Ross D, McClung MR. Bone mineral density in women aged 25-35 years receiving depot medroxyprogesterone acetate: recovery following discontinuation. Contraception. 2006;74:90-9.

13. Sirisha PSNRS. Efficacy of Depot medroxy Progesterone Acetate As A Contraceptive. 2017; 4(12).

14. Affandi B. Long-acting progestogens. Best Pract Res Clin Obstet Gynaecol. 2002;16(2):169-79.

15. Aktun H, Moroy P, Cakmak P, Yalcin HR, Leyla M, Danisman N. Depo-Provera: Use of A Long-acting
Progestin Injectable in Turkish Women Contraception. 2005;72(1):24-7.

16. Rai L, Prabaka P, Nair S. Injectable Depot Medroxy progesterone-A safe and effective contraception for an Indian Setting Health and Population-Perspectives and Issues. 2007;30(1):12-23.

17. Ruminjo JK, Sekadde-Kigondu CB, Karanja JG, Rivera R, Nasution M, Nutley T. Comparative acceptability of combined and progestin-only injectable contraceptives in Kenya. Contraception. 2005;72(2):138-45.

18. Wellings K, Zhihong Z, Krentel A, Barrett G, Glasier A. Attitudes towards long-acting reversible methods of contraception in general practice in the UK. Contraception. 2007;76(3):208-14.

19. Aladag N, Filiz M, Topsever P, Apaydin P, Gorpelioglu S. Satisfaction among women: differences between current users of barrier (male condom) and non-barrier methods. Eur J Contracept Reprod Health Care. 2006;11(2):81-8.

20. Prabhakaran S. Sweet A Self-administration of subcutaneous depot medroxyprogesterone acetate for contraception: feasibility and acceptability. Contraception. 2012;85:453-7.

Cite this article as: Samal S, Das L. Study of depot medroxyprogesterone acetate as an extended postpartum contraceptive at SCB medical college and hospital, Cuttack. Int J Reprod Contracept Obstet Gynecol 2021;10:1484-90. 